\title{
URBAN LIVING LABS FOR SENSITIVE CITY CULTURAL HERITAGE REGENERATION
}

\author{
DOI: 10.18485/arh_pt.2020.7.ch19
}

\section{_ Jasmina Siljanoska \\ Prof. PhD, Faculty of Architecture, University "SS. Cyril and Methodius", \\ Blvd. Partizanski odredi 24, Skopje, Macedonia, jasiljan@ukim.edu.mk}

\section{ABSTRACT}

The turn of the century was characterised by many different tendencies and shifting paradigms in theory and practices that affected the way the cities are planned and governed. Out of many present tendencies in the knowledge about the contemporary cities' future development, the sensitive city paradigm stands out as an effective way of transition from smart city because it has added the component of equity into equation. The sensitive city paradigm uses data innovation, artificial intelligence along with human consciousness in order to advance the decision-making processes in urban planning, while promoting discussion and inclusion of various stakeholders to find out solution.

In this respect the paper refers to the concept of living labs which perpetuate inclusive city and present a real-life test and experimentation environment. For the idea to be described the experiences and results carried out through the Skopje Urban Living Lab (SkULL), established as part of the ROCK (Regeneration and Optimisation of Cultural heritage in creative and Knowledge cities), European Union's Horizon 2020 project, have been used. The historic area of the city centre of Skopje, including the Old Bazaar, Medieval City Fortress and the immediate vicinity, presented demonstration area on which to develop collaborative and innovative ways of local citizens, businesses and other stakeholders' involvement in the processes of cultural heritage rehabilitation and re-utilisation.

The paper presented three core activities which have been carried out through the SkULL: 1. Those that supported the concept of "open" city, especially open data and open knowledge. In order to realise the idea a digital platform for open sources information on land use, property of the parcels and other cadastre information has been launched, as well information on different urban data collected through sensors and ICT tools; 2. Those that support and foster collaborative ideas and shared experiences for better understanding of the protected area development potentials and qualitative spatial re-use, by introducing ICT incubators and innovative technologies, as well creative industries and contemporary "crafts" as suppliers of new products and services. The dominant forms of the activities were "Open days" and the "Shops with history" initiative inauguration and 3 . Those that brought together multiple stakeholders (researchers, artists and students, citizens and local government) in creative workshops to participate in co-designing and co-shaping of the spaces/structures of the historic city.

KEYWORDS _ Sensitive City, Skopje Urban Living Lab, Cultural Heritage Regeneration, ROCK Project 


\section{INTRODUCTION}

The paper elaborated the ideas and utilized the findings of the ROCK (Regeneration and Optimisation of Cultural heritage in creative and Knowledge cities), a European Union's Horizon 2020 research and innovation programme funded project. The ROCK project followed the shift paradigm on global scale that moved the cities towards exploring new forms of collectivism and experience of sharing, simultaneously revealing the new potentials and relations of the emergent technologies' involvement in everyday life improvements. This general idea of the project was fully in line with the sensitive city paradigm which showed an effective way of transition from smart city, because in addition to smart city this city is able to sense, understand and respond to changes in its environments. The concept of sensitive city creates a new way to deal with urban planning and the effective operation of the networks, while promoting discussion and inclusion of informed participants to find out solutions that reflect the values of various stakeholders in the urban environment. (Greco and Bencardino, 2012)

The ROCK project primary interest was the transformation of three historic city centres (Bologna, Lisbon and Skopje) into creative and sustainable districts. ROCK vision for Skopje, in particular, was developed around the idea of transforming the historic area in the city centre (including the Old Bazaar, Medieval City Fortress and the surrounding area), into a knowledge, culture and technology-driven hub. The three specific demonstration areas of intervention were: The Old Bazaar area; 'Skopje Jewish quarter'; and the Skopje Medieval fortress. The project aimed at promotion of creative and ICT supported spatial practices, by bringing different stakeholders together in creative living labs to discuss and develop innovative working and business models based on collaborative and sustainable economy.
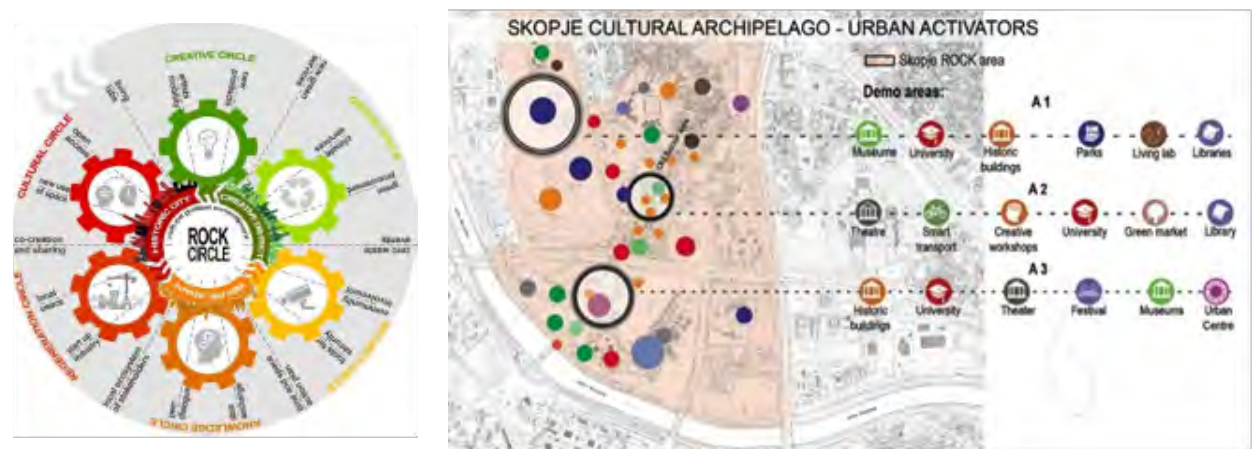

_ Figure 1 and 2: Cultural heritage in the ROCK circular system and ROCK Skopje demonstration areas

Skopje in the ROCK project participated with the idea of Cultural Archipelago. An overarching concept integrates different activities of knowledge and cultural heritage promotion, carried out through several Actions such as: Skopje Jewish quarter virtual guide, visualizing historic layers of the neighborhood and the Virtual Guide of Old Bazaar reinforced with augmented reality; Common sensing: provision of system of sensors and digital tools monitoring the microclimate, environmental features, light and sounds of the Old Bazaar and Festival of Light, organized as an annual social event; the Art Fortress, activities which aimed at extension of the innovative art practices and $\mathrm{CH}$ related events in the spatial realm between the Museum of Contemporary art and Skopje Medieval fortress and SkULL - Skopje Urban Living Lab, established as an open hub for transferring of ideas between the stakeholders and the municipalities in support of revitalisation of the Old Bazaar.

Skopje Urban Living Lab (SkULL) activities during the project implementation were focused primarily on the area of the Old Bazaar. But, among the other things, it was intended to extend the influence of the idea and the good practices of different activities exercised in the urban living laboratory beyond the limits of the Old Bazaar area, thus serving as an example for the entire city of Skopje. 


\section{URBAN LIVING LABS FOR SENSITIVE CITY}

The concept of urban living lab was novel to the regeneration practices in the Old Bazaar and in its conceptual setup it shared the same objectives with many others urban living labs that have been established for different reasons in the European cities. The best general description of the urban living labs tasks is that they refer to deployment of various methods and modes for social inclusion of the residents and other stakeholders in developing and trying out new possibilities and ways of operation in their daily life. Living labs are of critical importance for the rapid development of the cities and different social realities because they perpetuate inclusive city and present a real-life experimentation environment. This concept empowers citizens (end-users) as active co-creators to participate and get involved in the innovation process that should benefit the whole society. Urban living laboratory is supposed to act as a forum for innovation and dialogue in urban environments, focusing on solving real challenges in the area and bringing together in dialog multiple stakeholders and interests. Moreover, apart from finding and producing concrete solutions, the aim is to learn and exchange knowledge among the interested partners.

In this respect the paper referred to the experiences accomplished through the Skopje Urban Living Lab (SkULL). For the purpose of achieving collaborative setting and introducing innovative models of work and sustainable economic development for the regeneration area, new participants to the community of the Old Bazaar were invited. Actually, the essence of creating an effective Skopje urban living lab (SkULL) was mostly connected to initiating and developing a network of collaborative stakeholders, already involved and responsible for the vitality of the Old Bazaar, which might complement each other with knowledge, responsibilities and resources.

\section{SKOPJE URBAN LIVING LAB OBJECTIVES IN THE CITY CULTURAL HERITAGE REGENERATION}

Established Skopje Urban Living Lab (SkULL) utilised the territory of the Old Bazaar as a laboratory from which it is possible to learn about the concept of sharing and collaboration. In order to achieve synergies between the new technologies supported development and sustainable heritage led regeneration it was important to enable interaction and involvement of local citizens, businesses and other stakeholders in a socially inclusive process. As the Old Bazaar has functioned historically as an area in which the concepts of sharing and collaboration had been inherent to its spatial and functional resilience, it was logical to stand for and perpetuate this tradition in the search for innovative ways of involvement of local stakeholders in the regeneration of the area, while at the same time preserving and revitalising its social, economic and cultural distinctiveness.

The aim was to acknowledge the potential of the cultural and historic heritage protected area of the Old Bazaar through carefully taken actions towards different aspects of its regeneration, while adding new values, creative industries and technologies innovations in order to create new social and economic possibilities in multitude of social, economic and cultural diversity of the area.

Gradually, SkULL managed to become a platform for distributing and acquiring information, to fully involve the stakeholders in its activities and to start serving as a forum for dialogue and for innovative actions leading towards testing new technologies, policies and solutions for regeneration and urban planning.

It is important to mention that, unfortunately, the collaborative involvement into the planning processes led by the municipalities in the city of Skopje is insufficiently developed and it is characterised by poor communication and inclusion of various stakeholders in the decisions making process. Although there are formal mechanisms in place, the reality is far from satisfactory state of participatory planning. Not less important is that the Old Bazaar territory exists under divided authority, among the City of Skopje and the municipalities of Centar and Chair, and the ineffective communication among the different levels of the two-tier municipal government system in Skopje always presented a further obstacle in the organisation of certain activities initiated by SkULL. 
For this reason, when developing the programme of activities of SkULL, the starting point was to identify the gaps and constraints in the coordination and communication among the stakeholders in order to apply new approaches into the policies and practices of the municipalities and other governmental bodies and public agencies. The collaborative nature of urban living labs meant bringing together multiple stakeholders (researchers and artists, companies and business community, NGOs, citizens, politicians and local government officials) who were to complement each other with their diversity of competences, knowledge and skills, financial resources and political influence.

Another important fact about the area of the Old Bazaar is that it is a part of the historic area in Skopje and it is one of the oldest, but still active commercial zone and market place of the city. Most recently the area started losing its genuine creative socio-economic and cultural heritage values in a process of loosely controlled development, influenced by strong market oriented speculative actions. This tendency resulted in a gradual loss of its cultural identity, phenomena of marginalisation and degradation of its built stock, losing this way its importance in the city central area and acting only as a potential tourist destination submitted to the logics of consumption rather than being an integral part of the everyday life of the city centre.

Although the area is protected by the provisions of the Law on Protection of the Old Bazaar Cultural District, the actual control of the development process and the way the preservation measures are implemented, devalues the existing cultural heritage and decreases the chances for appropriate treatment of its socio-economic sustainability in the strategic spatial and economic planning documents of the local government.

Consequently, the real challenge before SkULL was to propose a variety of actions which would bring both immediate, but also long term benefits and changes, to stop the decay of the historic area by finding out new and appropriate approaches to design and regenerative uses that could re-establishing its spatial and economic vitality and bring life into the valuable cultural heritage setting. It is expected that the processes started in the SkULL will provide new insight into the potential and preservation of the heritage protected area by bringing opportunity for qualitative re-use and creative industries employed in the effort to replace the compromising and incompatible uses.

SkULL promoted various activities and new initiatives by implementing a network of local stakeholders in order to enable the processes of co-creation, joint decision making and shared responsibilities in the cultural heritage area development. By careful selection of actions and topics, in which different ROCK partners were involved, the SkULL managed to regain the interest of local shop owners and other interested parties who felt the potential of the area, but were gravely disappointed by its current state.

There were three major premises on which SkULL based its activities, which stem both from the nature of the living labs' approach, but also from the basic features of the concerned area:

- All actions were based on a participatory approach and social inclusion. SkULL made efforts to bring together multiple stakeholders - local citizens, artisans, artists, researchers, public organizations, citizens, companies, and local governments who complemented each other with the diversity of their competences, knowledge and skills. Aiming at providing a network of local ecosystem of stakeholders it was necessary to start with identifying all parties involved and in charge of the Old Bazaar regeneration. One of the first and most important tasks was the provision of open access to data including maps with planning, cadaster and conservation information which were crucial for the equal access of all stakeholders to basic information on which discussions and proposals were to be based. For this purpose, new data infrastructure was put in place which was easily accessible to all parties involved.

- The majority of actions were related to provision of new insight into the potential of the heritage protected area by exposing new opportunities for qualitative spatial re-use and re-design of neglected or underused areas and structures in the Old Bazaar. These actions addressed issues which were influencing the normal functioning of the area such as stationary traffic, increase of green areas, improving of accessibility, multifunctional use of public spaces, etc. In the context of traditional uses and space organization of individual shops and buildings efforts have been made to document the new possibilities for inclusion of contemporary "crafts" by way of involvement of artisan associ- 
ations and creative industry community.

- The adoption of regeneration measures utilizing ICT advantages included new technologies and new services in order to create new ways of mapping/accessing/appropriation of the cultural heritage by avoiding socio-environmental decay and improving safety perception, while taking into account market trends, new commercial opportunities and the compliance with the standards and regulation related the area of the Old Bazaar. These measures introduced new models of work, such as ICT incubators and collaborative workspaces, while creating new and reinforcing the existing local economy ecosystems, in order to allow for more viable business solutions that preserve the area by promoting sustainable and equitable economy.

Based on the above-mentioned premises SkULL undertook numerous activities in compliance with the ROCK objectives, testing different scenarios for involvement of the stakeholders and discussion environment on existing problems, as well as on propositions and solutions for development of the protected area of the Old Bazaar. The core activities organized and completed during the project period included: Open days: Thematic meetings and debates with different focus groups and stakeholders; Workshops of two different kinds: Design challenge workshops with graduate students from the Faculty of Architecture and Co-design workshops with the invited guest tutors from the cities with best practices; Open calls for competing with ideas: such is the "Shops with history" initiative; and ideas for new souvenirs on re-interpretation of the tradition crafts in a contemporary manner; Exibitions: Permanent and Temporary exhibitions; and Lectures and presentations, talks and debates with guest lecturers from the cities with best practices and other promotors of ideas.

Three main conceptual approaches used in the SkULL might be identified:

1: Activities that supported the concept of "open" city, especially open data and open knowledge: For a city to be inclusive it has to support the concept of "open" city, especially open data and open knowledge. In the context of modern technology use this means that the city is characterized by development of new useful services and open public databases for citizens and innovations that can improve the quality of life. As such, the advantages of modern technology through the e-services and web communication are used for mutual awareness and informing, as well as for inter-operability of databases with a sound impact on decision making.

For the idea of enabling availability of open data, which was identified as the most missing operational practice in the area, it was necessary to carry out a comprehensive survey on data collection. An access to open data on all important information and documents from different sources and instances dealing with the cultural heritage protection, urban planning and cadastre information was enabled. For this purpose a digital platform for open data and open sources information and comprehensive mapping on existing building stock by urban blocks, hight, bulc, land use, preservation plan status of the territory and the monuments, ownership status of the land parcels and cadastre information of the area, has been launched.
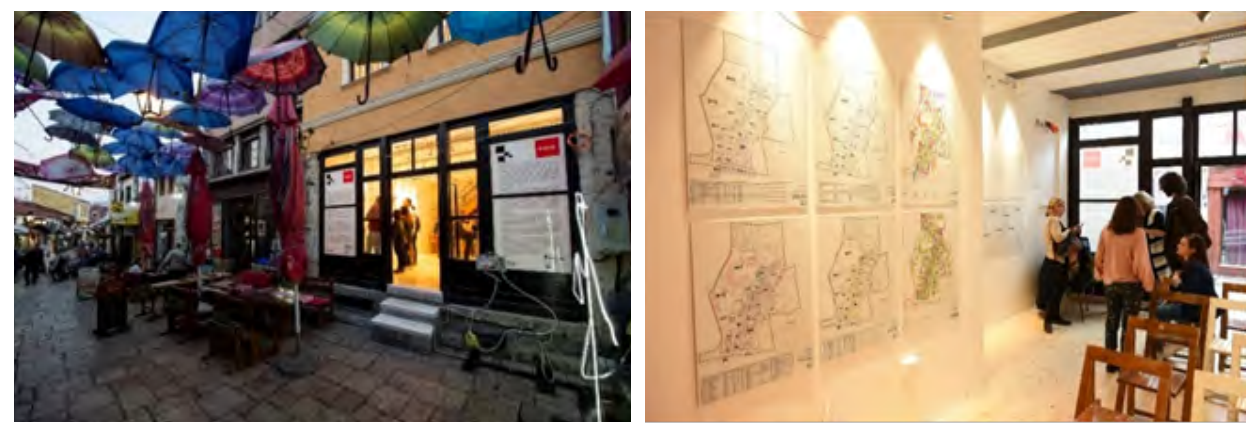

_ Figure 3 and 4: SkULL premises in the Old Bazaar and Permanent exibition on open data (source: S kULL, 2019) 
Aiming at better social inclusion and Open days have been organised, in support of the collaboration and dialog between the stakeholders. The idea was to enhance the community interaction and citizen participation, allowing them to actively disseminate information about the spaces they use and the problems they have, while enabling the municipalities to address future problems that dominate urban life in the manner of responsive urban planning and development of the area. For these purpose thematic Open days meetings have been organised in which different participants and stakeholders have discussed the problems and ideas for overcoming the situation. In addition to the institutions responsible for taking care of the Old Bazaar, such were planning and heritage protection officials, local government representatives from the city of Skopje, Centar and Chair, the key contributors were the owners of shops, citizens, craftsmen, various associations and NGOs whose activity is related to the Old Bazaar.

Another type of Open days presented different experiences and practices of the role model cities involved in the ROCK project. The idea was the community to benefit from the know-how of the Eindhoven, as a role model for their experiences with the living lab, especially the one that has been established in the former industrial regeneration area, which succeeded to rediscovered the place for industrial heritage. The other open day meeting was dedicated to sharing experiences from Athens, in particular of that how it was possible to embrace citizens' initiatives in the decision-making process of the civil society. The website platform of synAthina, which was developed as a public platform for connecting citizens and the ideas they submit, with the relevant local government representatives, non-governmental organizations and private businesses, as a result of this cooperation, is expected to get in operation in the near future in the city of Skopje, helping this way enhancement of the direct citizens inclusion.
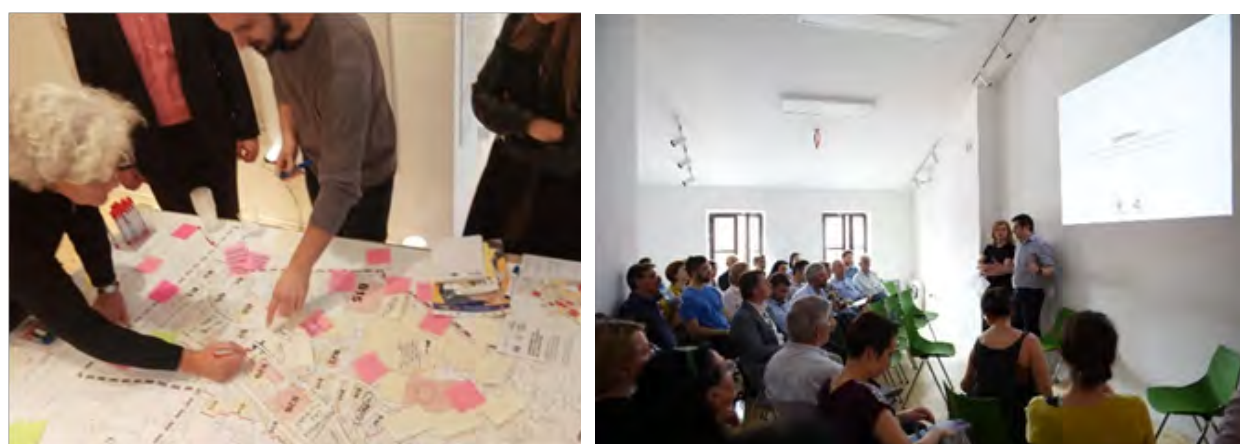

_ Figure 5 and 6: Co-design workshop with tutor from Eindhoven, Marianne Willemsen (source: SkULL, 2019)

2: Activities that supported and foster collaborative ideas by bringing opportunity for qualitative re-use and re-design, by introducing ICT and innovative technologies, or creative industries and contemporary "crafts". For this purpose, "Shops with history" initiative has been inaugurated, which aimed at presentation, documentation and redesign of existing shops with continuity in existence and capability of showing the history layers of the Old Bazaar. This Initiative assumed that certain crafts, which existed previously in the Old Bazaar, might be irrelevant in today's socio-economic development, but their remembrance is worth to be presented not only in the Museum of the Old Bazaar, but also in the existing premises of the shops. Likewise, in support of the creative industries and their innovative approach to improving the offer of souvenirs for the City of Skopje, and their creative re-interpretation of the traditional craft products representing the Old Bazaar specificity in a contemporary manner, an open call for ideas for new souvenirs has been launched. 

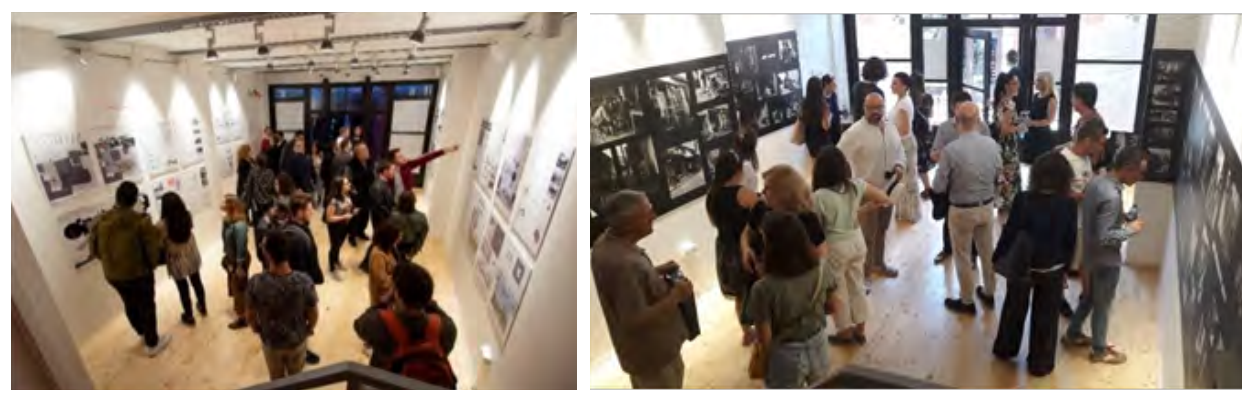

__ Figure 7 and 8: Design challenge workshop and "The Old Bazaar in the Past "exhibitions (source: SkULL, 2019)

3: Activities that supported creatve re-design and collaboration.

For this pupose several creative workshops have been organised and completed. Multiple stakeholders (researchers, artists and students, citizens and local government) have been brought together to participate in co-designing and co-shaping of the public spaces, abandoned or under used physical structures of the Old Bazaar. One type of workshops were carried out as Design challenge workshops on the Old Bazaar regeneration and transformation, which embraced new uses and design ideas proposed by graduate students from the Faculty of Architecture and the other type were Co-design workshops organised with the invited guest tutors from the cities with best practices set up within the ROCK network. New programmes for the Old Bazaar for different urban design tasks have been challenged such as: accessibility and movement improvement, transformation of public/ semi-public spaces and parking lots, new landscape design and greenery introduction, as well as transformation and re-design of the abandoned, or underused physical structures and shops.

\section{CONCLUSION}

The SkULL have successfully promoted various activities and new initiatives for the benefit of responsive led regeneration process, enabling inclusion and engagement of a wide range of participants in co-creation and joint decision making. The SkULL has managed to contribute to the important shift in comprehending the importance of civic engagement and that given opportunities can bring changes in the real world. The technology and creative industries driven regeneration process have already started showing results through novel digital platforms, urban data collected through sensors and ICT tools introduced. Undoubtably, SkULL has helped inclusive processes advancement and begun to utilize the place, knowledge and ICT infrastructure in the area of the Old Bazaar and it is expected it will continue to work as cultural, social and economic innovation lab and a resource centre for innovative business and sustainable development activities. Fortunately, the legacy of SkULL shall continue through the Skopje Urban Lab, that was already established by the City of Skopje. A great deal of follow-up activities have been applied already, but the lessons learnt from the results of SkULL should certainly, help in planning and designing the future activities. 


\section{REFERENCES}

- Арсовски, Тихомир. 1971. Стара скопска чаршија. Завод за станбено и коминално стопанисување: Скопје

_ Greco, Illaria and Bencardino, Massimiliano. 2012. Papers: "The paradigm of the Modern City: SMART and SENSEable Cities for Smart, Inclusive and Sustainable Growth". UN-Habitat - World Urban Forum: "The Urban Future": Naples

_ 1970. Skopje Resurgent. The Story of a United Nations Special Fund Town Planning Project. United Nations: New York.

- Stevens, Quentin. 2015, December. "Creative milieux: how urban design nurtures creative clusters". Journal of Urban Design 20 (1): 1-7

_ openlivinglabs.eu, European Network of Living Labs (ENoLL) Official website. Accessed Dec 12th, 2019. http://www.openlivinglabs.eu/livinglabs

_ ROCK: Regeneration and Optimisation of Cultural Heritage in creative and Knowledge cities. Accessed December 12th, 2019. https://rockproject.eu/about

_ Rock/ About. "Vision and Ambition." Accessed February 14th, 2020. https://rockproject.eu/about 